Systematic Review

\title{
Characteristics of the Middle Cervical Sympathetic Ganglion: A Systematic Review and Meta-Analysis
}

\begin{abstract}
Chan Park, MD ${ }^{1,2}$, Chong Hyun Suh, MD³, Ji Eun Shin, $\mathrm{MD}^{4}$, and Jung Hwan Baek, MD, PhD 3
From: Department of

Radiology, Namwon Medical Center, Republic of Korea; 2Department of Radiology, Chonnam National University Hospital, Republic of Korea; 3Department of Radiology \& Research Institute of

Radiology, University of Ulsan College of Medicine, Asan Medical Center, Republic of Korea; ${ }^{4}$ Department of Radiology, CHA University College of Medicine, Gangnam CHA Hospital, Republic of

Korea

Address Correspondence: Jung Hwan Baek, MD, PhD Department of Radiology \& Research Institute of Radiology, University of Ulsan College of Medicine, Asan Medical Center 86 Asanbyeongwon-Gil, Songpa-Gu, Seoul 05505, Korea

E-mail: radbaek@naver.com

Disclaimer: There was no external funding in the preparation of this manuscript.

Chan Park and Chong Hyun

Suh contributed equally to this work. Conflict of interest:

Each author certifies that he or she, or a member of his or her immediate family, has no commercial association (i.e., consultancies, stock ownership, equity interest, patent/licensing arrangements, etc.) that might

pose a conflict of interest in connection with the submitted manuscript.

Manuscript received: 11-14-2016

Revised manuscript received: 04-01-2017

Accepted for publication: 05-01-2017

Free full manuscript: www.painphysicianjournal.com

Background: Understanding the characteristics of the middle cervical sympathetic ganglion (MCSG) may minimize procedure-related complications and maximize efficacy during surgery or ultrasound (US)-guided procedures. The location and detection rate of the MCSG were variable in small population studies. Therefore, a large population study or meta-analysis could give more information about the MCSG.

Objectives: We aim to review the published literature and evaluate the anatomical features of the MCSG, including the detection rate, location, size, and a normal variation, and to review the clinical relevance of MCSG for procedures including, US-guided ganglion block, ethanol ablation (EA), or radiofrequency ablation (RFA)

Study Design: A systematic review and meta-analysis. The Ovid-MEDLINE and EMBASE databases were searched to find the detection rate, location, and other characteristics of the MCSG.

Setting: The pooled proportions for the detection rate of the MCSG were assessed using the DerSimonian-Laird random-effects model.

Methods: Heterogeneity among the studies was determined using a chi-square analysis for the pooled estimates and inconsistency index $\left(1^{2}\right)$. In order to reduce the heterogeneity, sensitivity analyses were performed.

Results: A review of 542 studies identified 8 eligible studies, with 273 MCSGs included in the meta-analysis. The pooled proportion for the detection rate of the MCSG was $50.4 \%$ (95\% confidence interval $[\mathrm{Cl}], 34.5-66.4 \%)$. Considerable heterogeneity among the studies was observed $\left(I^{2}=94.9 \%\right)$. In the sensitivity analysis, when excluding one study, heterogeneity was reduced with a recalculated pooled proportion of $44.2 \%\left(95 \% \mathrm{Cl}, 32.1-56.2 \%\right.$; $\left.\mathrm{I}^{2}=86.0 \%\right)$. The location of the MCSG is usually posterior to the carotid sheath and anterior to the longus colli muscle at the level of the C3-C7 vertebrae. There was a variant where the cervical sympathetic trunk was located at the posterior wall of the carotid sheath and was adherent to the sheath. The size of the MCSG is as follows: the width, length, and height ranges were 3.8-6.3 mm, 6.3-10.5 $\mathrm{mm}$, and 1.7-2.1 mm, respectively. A specific type of MCSG, referred to as the "double middle cervical ganglion", consisting of 2 ganglia, was demonstrated in 3 studies with a detection rate of $2.9-10 \%$.

Limitations: This meta-analysis included a relatively small number of studies. Significant heterogeneity was also present in the detection rate of MCSG in these studies. There was a lack of concentrated information about the MCSG, because the majority of the included studies focused on the entire cervical sympathetic chain, not only MCSG primarily. Improving complication rates might be limited due to the approximate $50 \%$ detection rate.

Conclusion: Understanding the characteristics and variations of the MCSG could minimize complications and maximize efficacy during surgery and US-guided procedures.

Key words: Middle cervical sympathetic ganglion, cervical sympathetic trunk, cervical sympathetic chain, ultrasound, nerve block, ethanol ablation, radiofrequency ablation, thyroid, Horner syndrome, meta-analysis
\end{abstract}

Pain Physician 2018; 21:9-18 
T he cervical sympathetic chain is typically located posteromedial to the carotid sheath and passes over the longus colli muscle (1). Part of the cervical sympathetic chain, the middle cervical sympathetic ganglion (MCSG) is located on the longus colli muscle, anterior to the transverse process of the C6 vertebra.

There is growing clinical significance of minimally invasive procedure. Owing to its location, the MCSG is sometimes damaged during surgery or various procedures such as neck lymph node biopsy, ethanol ablation (EA), and radiofrequency ablation (RFA) of thyroid tumors (2-6). Knowing relevant anatomy and meticulous inspection using ultrasound (US) before procedures, such as nerve blocks or RFAs, is needed to reduce procedure-related complications.

Although several studies using cadavers or US evaluated the characteristics of the MCSG $(1,2,7-12)$, the location and detection rate were variable in small population studies. Understanding the characteristics of the MCSG may minimize procedure-related complications and maximize efficacy during surgery or USguided procedures. Therefore, a large population study or meta-analysis could give more information about the MCSG.

To our knowledge, our present systematic review and meta-analysis is the first to assess the characteristics of the MCSG. This study aimed to review the published literature and evaluate the anatomical features of the MCSG including the detection rate, location, size, and a normal variation, as well as review the clinical relevance of the MCSG for procedures including US-guided ganglion block, EA, or RFA.

\section{Methods}

\section{Literature Search Strategy}

A computerized search of the MEDLINE and EMBASE databases was performed to find relevant original studies evaluating the MCSG. The following search terms were used: ("cervical sympathetic ganglion" OR "cervical sympathetic trunk" OR CSG) AND (ultrasonography OR ultrasound OR US OR anatomy OR neuroanatomy OR sonoanatomy OR cadaver OR cadaveric). There was no initial data set in the search parameters. The literature search was performed for articles published until June 7, 2016. Our search was limited to studies in English. The bibliographies of the selected studies were screened to identify other relevant articles.

\section{Inclusion Criteria}

Studies or subsets of studies assessing the detection rate of the MCSG were eligible for inclusion. Studies including all of the following criteria were included:

- Population: studies evaluating the MCSG in human cadavers or patients undergoing neck US, with studies containing data for at least 10 cadavers or patients included

- Reference standard: regarding cadaveric studies, the MCSG was observed, located posteromedial to the carotid sheath and running on the longus muscles. In terms of US studies, the MCSG is defined as an oval-shaped hypoechoic structure that is connected with 2 or more hypoechoic linear structures, adjacent to the common carotid artery and inferior thyroid artery at the level of C5-C7 (11)

- Study designs: all observational studies (retrospective or prospective)

- Outcomes: results that demonstrated an adequate amount of detail to appraise the detection rate of MCSGs.

\section{Exclusion Criteria}

The exclusion criteria were as follows:

- Case reports and case series with fewer than 10 individuals or studies with a possible selection bias, e.g., non-consecutive series of patients

- Editorials, review articles, comments, letters, and conference proceedings

- Studies which had studied something other than the detection rate of the MCSG

- Studies with overlapping data and patients.

Two reviewers (C.P. and C.H.S.) selected literature reports separately using a standardized form.

\section{Data Extraction}

We extracted the following data from each of the selected studies and added them to standardized data forms:

- Study characteristics: the authors, year of publication, study design, hospital or medical school, duration of patient enrollment, and sample size

- Demographic characteristics of populations: patients or cadavers, mean age, and examination method

- The detection rate, width, length, height, and location of the MCSG.

One reviewer (C.P.) extracted data from the studies, and the second reviewer (C.H.S.) confirmed the accuracy of the aforementioned data. 


\section{Quality Assessment}

The methodological quality of the included studies was separately analyzed by 2 reviewers (C.P. and C.H.S.) using a customized questionnaire based on the Quality Assessment of Diagnostic Accuracy Studies-2 (QUADAS-2) criteria (13).

\section{Data Synthesis and Statistical Analysis}

The detection rate of the MCSG was adopted as the main outcome for this meta-analysis. Meta-analytic pooling was based on the inverse variance method for calculating weights and pooled proportions, and their 95\% confidence intervals $(\mathrm{Cl})$ were determined using the DerSimonian-Laird random-effects model (14-16). Heterogeneity among the studies was determined by using the chi-square analysis for the pooled estimates $(P<0.05$ indicating significant heterogeneity) and the inconsistency index $\left(\mathrm{I}^{2}\right)(0-40 \%$ might not be important, 30-60\% may represent moderate heterogeneity, 50-90\% may represent substantial heterogeneity, and 75-100\% represents considerable heterogeneity) $(17,18)$. Publication/ reporting biases were visually assessed using funnel plots and significance was determined using Egger's test (19). Publication bias-adjusted pooled estimates, i.e., adjusted pooled proportions, were also obtained using the trimand-fill method (20). If the original unadjusted pooled proportion and the trim-and-fill adjusted pooled proportion agreed, the results were regarded as robust for publication bias. All statistical analyses were performed using $R$ version 3.0.2 (The R Foundation for Statistical Computing) with the "metafor" and the "mada" packages.

\section{Results}

\section{Literature Search}

The study selection process is shown in Fig. 1. The literature search of the Ovid-MEDLINE and EMBASE databases identified 542 articles; after removing du-

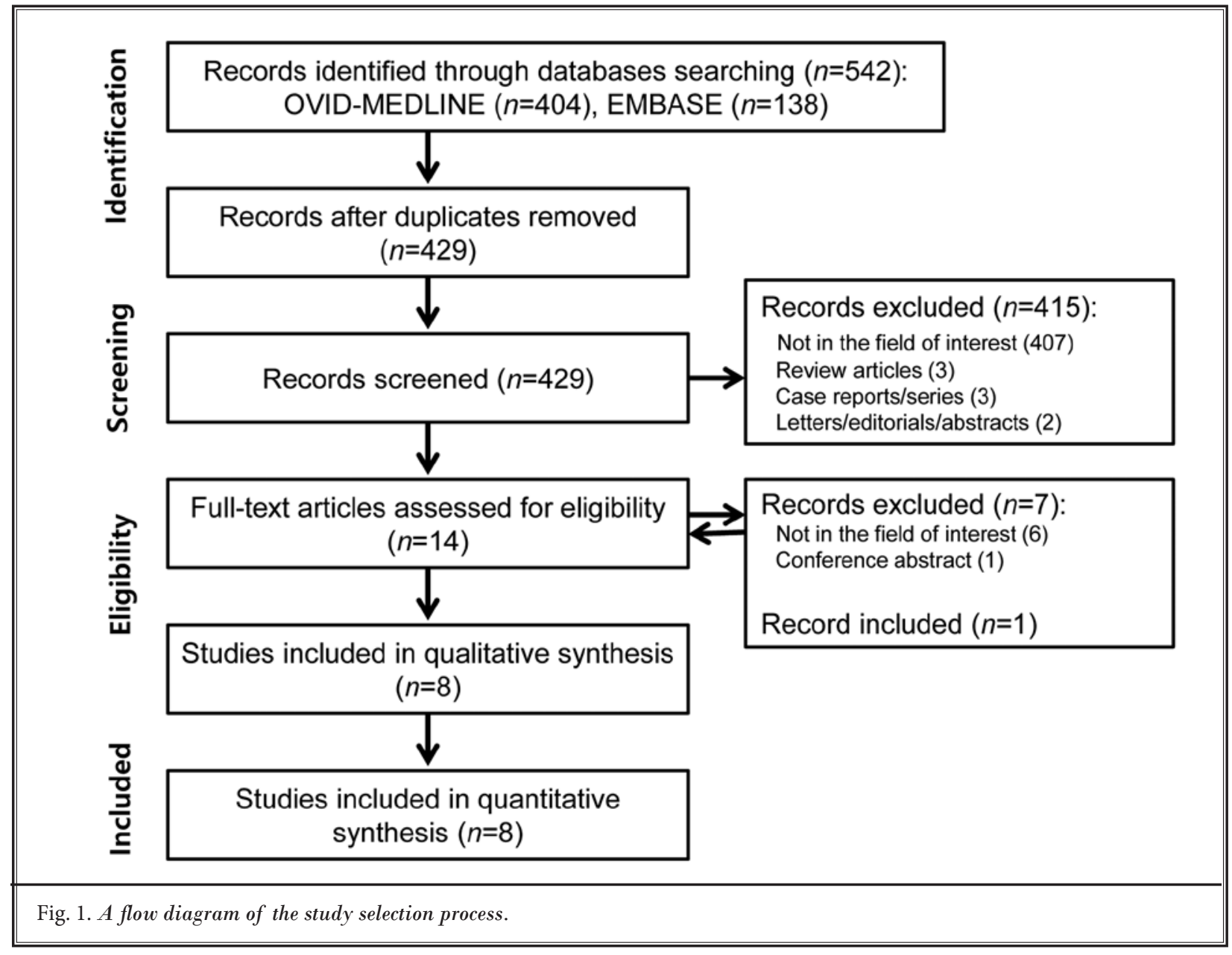


plicates, 429 articles were screened for eligibility. Of those, 415 were excluded after review of their titles and abstracts, including 3 review articles, 3 case reports, 2 letters, editorials, or conference abstracts, and 407 articles not in the field of interest of this study. The full-text versions of the remaining 14 articles were reviewed; a search of their bibliographies found an additional eligible study. Of these 14 articles, 7 were further excluded after reviewing their full texts, i.e., 6 studies that were not in the field of interest (21-26) and one study with a conference abstract. Finally, 8 eligible studies were included in this meta-analysis $(1,2,7-12)$.

\section{Characteristics of the Included Studies}

The detailed characteristics of the 8 included studies are summarized in Table 1 . Seven of the 8 studies used cadaveric dissection $(1,7-10,12)$ and the other was a prospective study using US (11). The mean population ages ranged from 41 to 76.5 years. Five of the 7 cadaveric studies performed bilateral neck dissection (2,7-12). Another study only performed right-sided neck dissection (1). The other study did not discuss the details of the neck dissection, e.g., unilateral or bilateral (2).

The US features of the MCSG were defined as follows: a longitudinally elongated hypoechoic structure with a connection to 2 or more linear hypoechoic structures, which were regarded as sympathetic nerves (11). Overall, the quality of the included studies was moderate as assessed by the QUADAS-2 tool, with all of the studies satisfying 5 or more of the total of 7 items (13) (Fig. 2).

\section{The Characteristics of the MCSG}

The 8 studies included in the analysis detected 273 MCSGs. The meta-analytic pooled proportions for the detection rate of the MCSG are summarized in Table 2 , and the corresponding forest plots are illustrated in Fig. 3. The pooled proportion for the detection rate of the MCSG was $50.4 \%(95 \% \mathrm{Cl}, 34.5-66.4 \%)$. Considerable heterogeneity among the studies was observed $\left(I^{2}=94.9 \%\right)$. One study (8) reported a detection rate of the MCSG $(91.7 \%)$ that was much higher than that of the other 7 studies $(1,2,7,9-12)$. Differing from the other studies, the entire autonomic cardiac nervous system was evaluated using a stereomicroscope (8). In the sensitivity analysis, when excluding the former study, heterogeneity was reduced with a recalculated pooled proportion of $44.2 \%\left(95 \% \mathrm{Cl}, 32.1-56.2 \% ; \mathrm{I}^{2}=\right.$ $86.0 \%)$. In addition, we performed another sensitivity analysis which excluded the one study using US (11).
The recalculated pooled proportion was $52.8 \%(95 \%$ $\mathrm{Cl}, 33.6-70.0 \%$ ).

The location of the MCSG was usually posterior to the carotid sheath and anterior to the longus colli muscle at the level of the C3-C7 vertebrae (Fig. 4) (1,812). There was an extraordinary case where the cervical sympathetic trunk was located at the posterior wall of the carotid sheath, adherent to the sheath (8.33\%) (Fig. 4D) (9). Shin et al (11) described 2 anatomic variants of the location of the ganglion, medial, and lateral types. The lateral type $(88 \%)$ is the more common type and is located posterior to the carotid sheath (Fig. 4A). In contrast, the medial type (12\%) is located between the thyroid gland and the common carotid artery (Fig. 4B). The size of the MCSG was as follows: the width, length, and height ranges were $3.8-6.3 \mathrm{~mm}, 6.3-10.5 \mathrm{~mm}$, and 1.7-2.1 mm, respectively. A specific type of MCSG, referred to as the "double middle cervical ganglion", consisting of 2 ganglia, was seen in 3 studies with a detection rate of $2.9-10 \%$ (Fig. 4C) (10-12).

\section{Discussion}

Our present meta-analysis demonstrated that the pooled proportion for the detection rate of the MCSG was $50.4 \%$. It is typically located at the level of C5-C7, usually anterior to the longus colli muscle; however, the cervical sympathetic chain can pass within the posterior wall of the carotid sheath. The double ganglion, a specific type of MCSG, was noted in $2.88-10 \%$ of cases in 3 studies. Understanding the characteristics and variations of the MCSG could minimize procedure-related complications and maximize efficacy during US-guided procedures.

Our meta-analysis found that the detection rate of the MCSG was $50.4 \%$. However, the detection rate of the ganglion is variable between studies. Yin et al (12) reported a low detection rate of $21.88 \%$, while Kawashima (8) reported a detection rate of $91.67 \%$, a high detection rate that was explained through the use of microscopic evaluation of the ganglion in cadavers. The MCSG is typically small and could be found at multiple locations in the sympathetic trunk between the superior and inferior cervical ganglia $(27,28)$. Therefore, detection of this ganglion is frequently difficult in cadaveric studies and surgical procedures. In a USguided procedure, it is very difficult to confirm that the structure is definitively the sympathetic ganglion if its size is very small. If the physician cannot find the MCSG during neck surgery or a US-guided procedure, extra attention should be paid. 


\begin{tabular}{|c|c|c|c|c|c|c|c|c|}
\hline 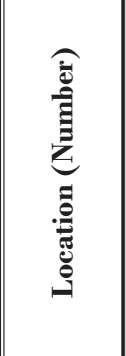 & $\frac{\overleftrightarrow{z}}{\breve{z}}$ & $\overleftrightarrow{\breve{z}}$ & 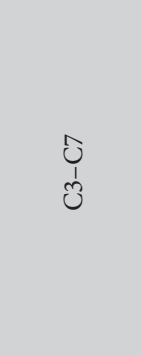 & 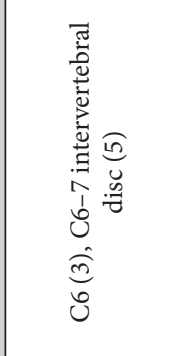 & 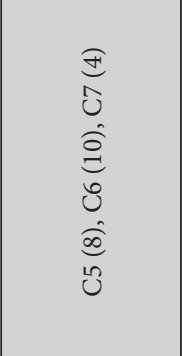 & 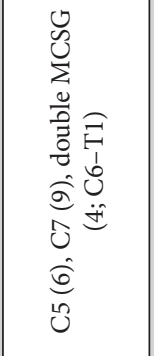 & 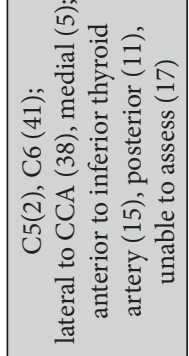 & 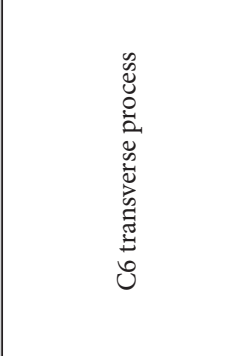 \\
\hline 昰高 & $\frac{\overleftrightarrow{z}}{\bar{z}}$ & $\underset{\mathrm{Z}}{\mathbb{Z}}$ & $\overleftrightarrow{\mathbb{Z}}$ & $\begin{array}{l}\infty \\
i \\
+1 \\
\stackrel{i}{i}\end{array}$ & $\overleftrightarrow{\mathbb{z}}$ & $\overleftrightarrow{\mathrm{z}}$ & $\begin{array}{l}\hat{0} \\
+1 \\
+ \\
\hat{j}\end{array}$ & 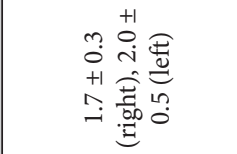 \\
\hline 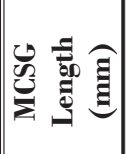 & 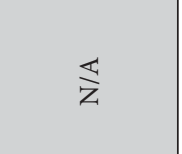 & $\begin{array}{l}\vec{i} \\
+1 \\
\stackrel{1}{a}\end{array}$ & $\overleftrightarrow{\mathrm{z}}$ & $\begin{array}{l}\stackrel{+}{\infty} \\
+1 \\
\stackrel{1}{a}\end{array}$ & 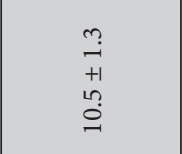 & $\begin{array}{l}\ddot{H} \\
i \\
+1 \\
\infty \\
\infty\end{array}$ & $\begin{array}{l}\stackrel{1}{\infty} \\
+1 \\
+\infty \\
\infty\end{array}$ & 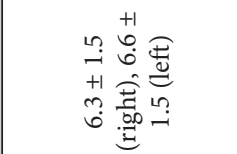 \\
\hline 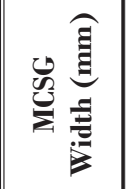 & 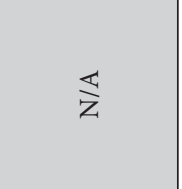 & $\begin{array}{l}m \\
\stackrel{m}{+1} \\
i \\
i n\end{array}$ & $\overleftrightarrow{\mathrm{Z}}$ & $\begin{array}{l}-7 \\
+1 \\
+1 \\
0 \\
\text { in }\end{array}$ & $\begin{array}{l}0 \\
0 \\
+1 \\
\\
0\end{array}$ & $\begin{array}{l}\vec{i} \\
+\overrightarrow{1} \\
\overrightarrow{i n}\end{array}$ & $\begin{array}{l}n \\
\rightarrow+1 \\
+\infty \\
\infty \\
\tilde{m}\end{array}$ & 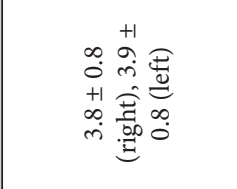 \\
\hline 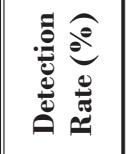 & $\begin{array}{c}\tilde{\omega} \\
\tilde{n}\end{array}$ & ते & $\begin{array}{l}\hat{b} \\
\dot{a}\end{array}$ & $\stackrel{m}{m}$ & $\stackrel{m}{n}$ & $\begin{array}{l}\text { 号 } \\
\stackrel{+}{+}\end{array}$ & $\stackrel{\stackrel{n}{m}}{\vec{F}}$ & $\begin{array}{l}\infty \\
\infty \\
\stackrel{\sim}{i}\end{array}$ \\
\hline 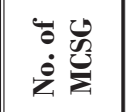 & $\widetilde{\beth}$ & $=$ & $\tilde{m}$ & $\infty$ & $\approx$ & 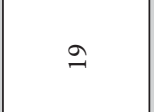 & $\dddot{F}$ & $\exists$ \\
\hline 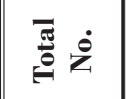 & 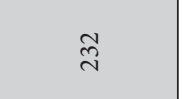 & $\stackrel{\infty}{\sim}$ & $\stackrel{m}{\infty}$ & $\stackrel{\leftrightarrow}{\sim}$ & i & or & 苛 & 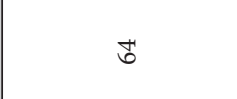 \\
\hline 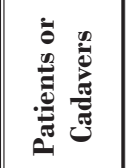 & 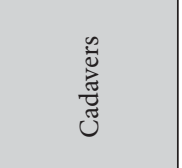 & 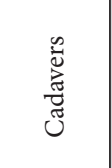 & 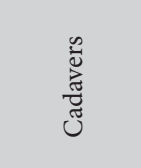 & 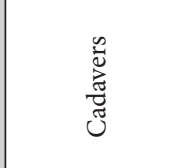 & 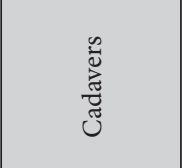 & 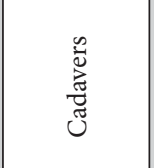 & 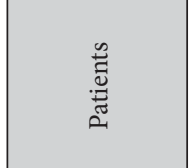 & 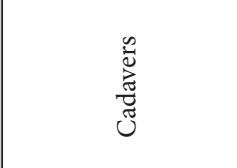 \\
\hline 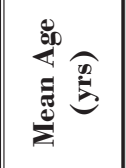 & 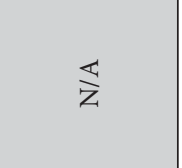 & $\begin{array}{l}n \\
\stackrel{0}{0}\end{array}$ & $\overleftrightarrow{\mathrm{z}}$ & $\overleftrightarrow{\mathrm{z}}$ & $F$ & $\overleftrightarrow{\Delta}$ & $\begin{array}{l}\text { in } \\
\text { fin }\end{array}$ & in \\
\hline 告 & 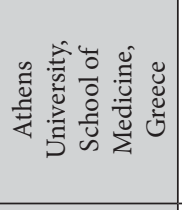 & 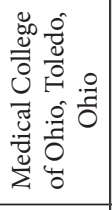 & 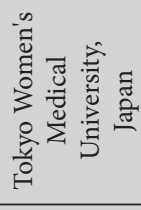 & 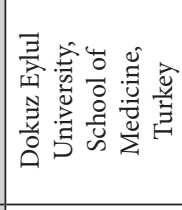 & 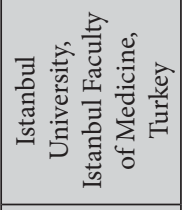 & 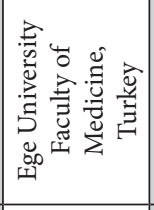 & 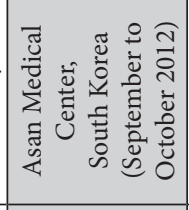 & 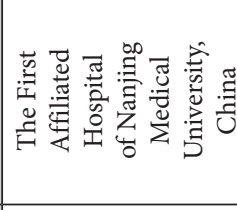 \\
\hline 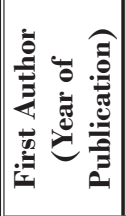 & 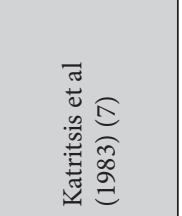 & 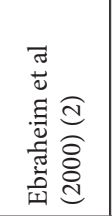 & 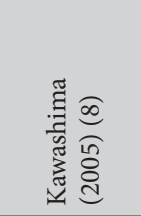 & 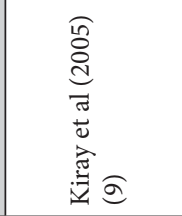 & 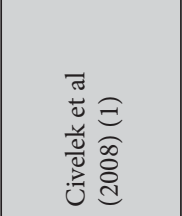 & 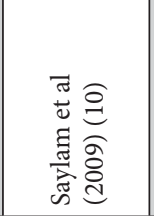 & 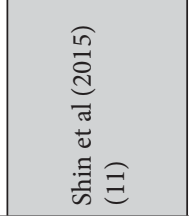 & 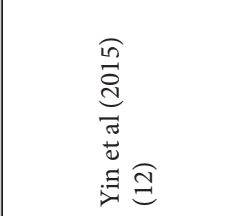 \\
\hline
\end{tabular}




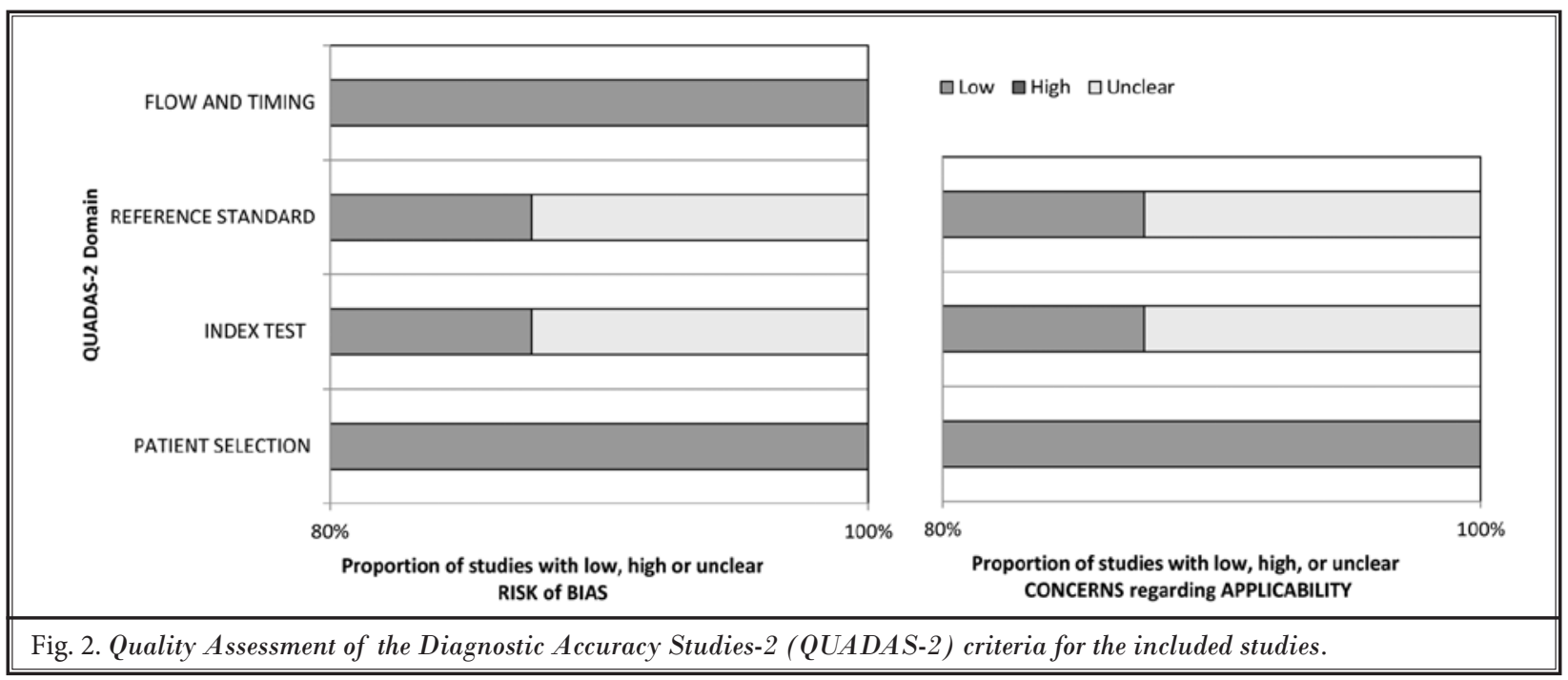

Table 2. Summary of the meta-analytic pooled proportions for the detection rate of the MCSG.

\begin{tabular}{|c|c|c|c|c|c|c|c|c|}
\hline & \multirow[b]{2}{*}{$\begin{array}{l}\text { No. of } \\
\text { Studies }\end{array}$} & \multirow[b]{2}{*}{$\begin{array}{l}\text { No. of } \\
\text { Cases }\end{array}$} & \multicolumn{3}{|c|}{ "Summary Estimate } & \multirow[b]{2}{*}{$\begin{array}{c}P \text {-valuet for } \\
\text { Reporting } \\
\text { Bias }\end{array}$} & \multicolumn{2}{|c|}{ Trim-and-Fill Estimate } \\
\hline & & & $\begin{array}{c}\text { Pooled } \\
\text { Proportion } \\
(95 \% \text { CI })\end{array}$ & $\begin{array}{c}P \text {-value for } \\
\text { Heterogeneity* }\end{array}$ & $\mathbf{I}^{2} \% \S$ & & $\begin{array}{l}\text { No. of } \\
\text { Missing } \\
\text { Studies }\end{array}$ & $\begin{array}{c}\text { Adjusted } \\
\text { Pooled } \\
\text { Proportion } \\
\text { (95\% CI) }\end{array}$ \\
\hline $\begin{array}{l}\text { All Included } \\
\text { Studies }\end{array}$ & 8 & 558 & $\begin{array}{c}50.4 \% \\
(34.5-66.4 \%)\end{array}$ & $<0.01$ & $94.9 \%$ & 0.5906 & 1 & $\begin{array}{c}54.7 \% \\
(38.4-70.9 \%)\end{array}$ \\
\hline \begin{tabular}{|l} 
Sensitivity \\
Analysis Excluding \\
Kawashima Study
\end{tabular} & 7 & 522 & $\begin{array}{c}44.2 \% \\
(32.1-56.2 \%)\end{array}$ & $<0.01$ & $86.0 \%$ & 0.9175 & & \\
\hline $\begin{array}{l}\text { Sensitivity Analysis } \\
\text { Excluding Shin et } \\
\text { al Study }\end{array}$ & 7 & 454 & $\begin{array}{c}52.8 \% \\
(33.6-70.0 \%)\end{array}$ & $<0.01$ & $94.2 \%$ & 0.5196 & & \\
\hline
\end{tabular}

${ }^{\star} P$-value by the Cochran $\mathrm{Q}$ method to test the heterogeneity of the pooled data, with $P<0.05$ indicating substantial heterogeneity.

$\S$ Higgin’s index for heterogeneity (0-40\% might not be important, 30-60\% may represent moderate heterogeneity, 50-90\% may represent substantial heterogeneity, and $75-100 \%$ represents considerable heterogeneity).

$\dagger$ Test of publication/reporting bias using Egger's test, with $P<0.10$ indicating significant bias.

The cervical sympathetic chain contains 2 to 4 ganglia, including the superior, middle, inferior cervical/cervicothoracic, and vertebral ganglia. The superior cervical ganglion is the largest and consistent ganglion of the cervical sympathetic chain (1). It is a vertically oriented ovoid or fusiform-shaped structure (29). It is located posterior to the bifurcation of the common carotid artery, between the $\mathrm{C} 1$ and $\mathrm{C} 4$ level and lies about the hyoid bone level $(1,8,29)$. Lee et al $(29)$ reported that $73 \%$ of superior cervical ganglion could be identified in medial to internal carotid artery and lateral to longus capitis muscle at the C2-C3 level using $3 \mathrm{~T}$ magnetic resonance imaging (MRI) (29). Typical location and intraganglionic hypointensity on a T2- weighted image and a contrast enhanced T1-weighted image could be utilized as imaging clues for differentiating superior cervical ganglion from retropharyngeal metastatic lymphadenopathy $(29,30)$. The inferior cervical ganglion with or without fusion to the thoracic ganglia is located between $C 7$ and T1 (8). The inferior cervical ganglion blends with the thoracic ganglia and forms the cervicothoracic ganglion (9). The vertebral ganglion, which is the smallest ganglion of the cervical sympathetic chain, lies anteromedial to and is adjacent to the vertebral artery and is not as well-defined as the other ganglia (9). Damage to the cervical sympathetic chain can cause Horner syndrome, characterized by ipsilateral miosis, ptosis, and anhidrosis. 


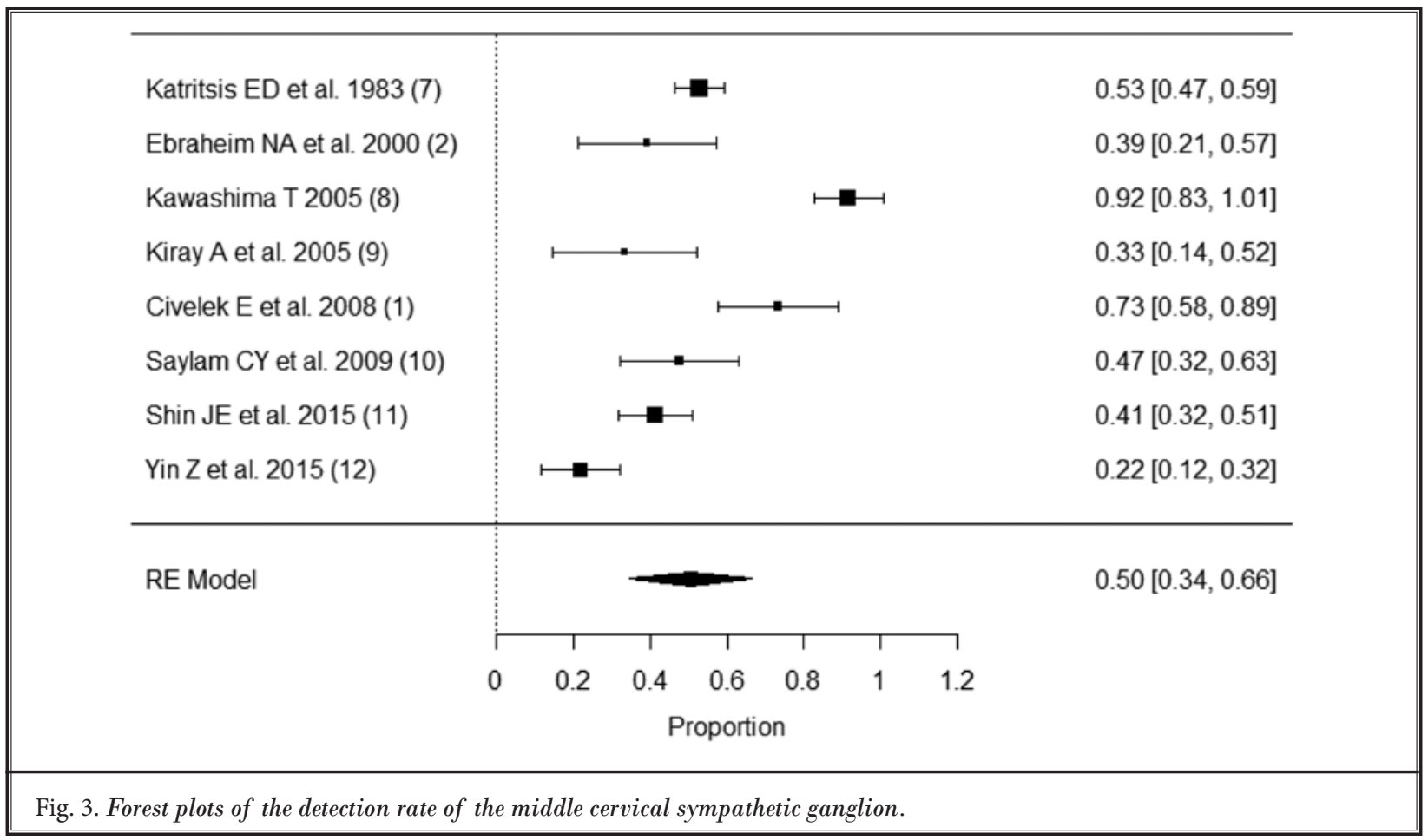

Regarding the location of the cervical sympathetic ganglion, it is usually located posteromedial to the carotid sheath and passes over the longus muscle. It extends longitudinally from the longus capitis to the longus colli, over the muscles and under the prevertebral fascia (1). The ganglion may also be placed within the carotid sheath and abutting the posterior wall of the sheath $(8.33-16.67 \%)(9,31)$. Such a variation may cause damage to the cervical sympathetic chain when the carotid artery is laterally retracted, even during an anterior approach to the cervical spine (9). Regarding the relationship between the inferior thyroid artery and sympathetic ganglion, there are both anterior and posterior types. The posterior type, where the ganglion lies posterior to the inferior thyroid artery, has been reported in $26-75 \%$ of cases $(10,11)$. Regarding the relationship between the common carotid artery and the sympathetic ganglion, there are medial and lateral types. US-guided ablations, EA, or RFA of thyroid lesions can also cause Horner syndrome $(3,5,6,11,32,33)$. During EA for benign thyroid nodules, leakage of ethanol outside the thyroid gland can damage the ganglion directly (3). Direct thermal damage to the ganglion during RFA of benign and recurrent thyroid cancers has also been reported $(5,6,11,32,33)$. The medial type MCSG adjoins the thyroid gland; US-monitoring of this ganglion with a hydrodissection technique (injection of $5 \%$ D/W between the thyroid tumor and ganglion) could prevent thermal damage $(6,11,34)$.

Anterior surgical approaches to the cervical spine or cervicothoracic junction can cause Horner syndrome with an incidence ranging from $0.2-4 \%$ (35-41). This syndrome affects mainly the anterolateral part of the cervical spine, particularly when stripping of the longus colli muscle or dissection extends to this muscle (2). The lateral retraction of the longus colli muscle, carotid sheath, or both to expose the lateral portion of the cervical spine causes stretching of the sympathetic trunk and may lead to damage, resulting in temporary or permanent Horner syndrome (2). The careful approximation of the medial border of the longus colli muscle and MCSG should be considered during retraction or dissection of the longus colli muscle in anterior cervical spine surgery (1).

During US-guided ganglion block, direct visualization and monitoring of the MCSG on US enables the exact injection of the anesthetic around the ganglion. This technique may minimize the amount of anesthetic injected, complications, and total procedure time (11). Shin et al (11) suggested 2 types of ganglion in terms of their location, medial, and lateral types. The medial type MCSG was observed in $12 \%$ of the cases, abutting 


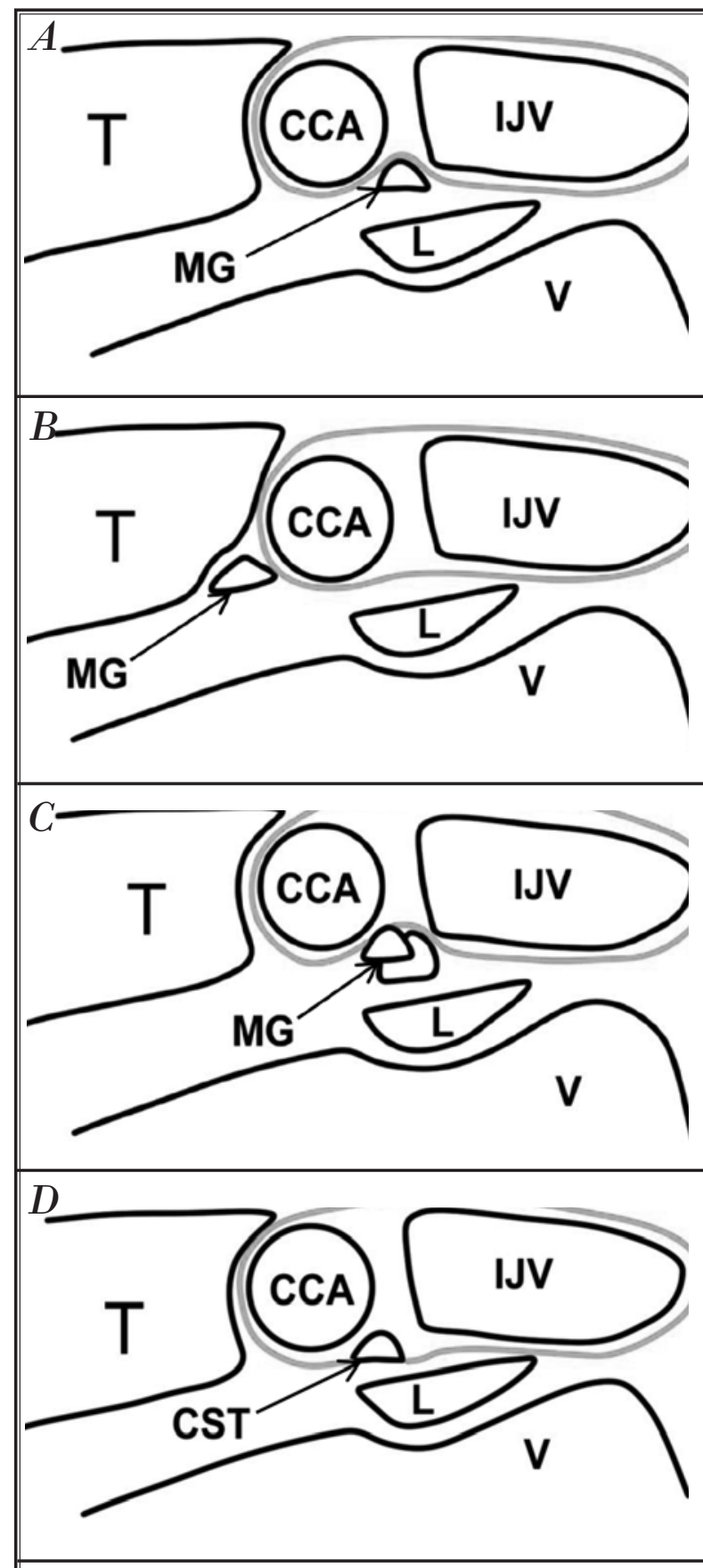

Fig. 4. Schematic drawings of the anatomical variations of the MCSG and cervical sympathetic trunk. A. Lateral type, which is more the common type and is located lateral to the common carotid artery (CCA) and posterior to the carotid sheath. B. Medial type, which is located between the thyroid gland and the CCA. C. Double ganglia, which is composed of 2 ganglia. D. The cervical sympathetic trunk is located within the posterior wall of the carotid sheath, and it is adherent to the sheath. the thyroid gland (11). In medial type MCSGs, the location of the injection of anesthetics should be different compared with that of the lateral type $(11,24)$. In addition, monitoring of the relationship between the ganglion and inferior thyroid artery could also minimize hemorrhage during ganglion block (42).

latrogenic injury to the MCSG is possible during neck biopsy or fine needle aspiration. The development of Horner syndrome after neck lymph node fine-needle aspiration has been reported (4). Al-Abbadi et al (43) suggested that direct injury to the ganglion during lymph node biopsy can cause Horner syndrome. We believe that the MCSG can be confused with a lymph node because of its oval shape and location. In individuals with a large MCSG, it could be confused with a metastatic lymph node, conceivably leading to unnecessary biopsy (33). Different from lymph nodes, the MCSG is connected with multiple linear hypoechoic sympathetic nerves and does not have echogenic hilum or hilar vascularity on Doppler US (11). Regarding the superior cervical sympathetic ganglion, there is a report of concerning the misdiagnosis of the superior cervical sympathetic ganglion as a recurrent malignant lymph node (44). The superior sympathetic ganglion can also be confused for a metastatic lymph node; however, the superior cervical sympathetic ganglion also shows typical US and MRI findings, and physicians can differentiate it from a metastatic lymph node $(29,44)$. Therefore, awareness of these features is essential for US-guided neck biopsy.

Our study had several limitations. First, it included a relatively small number of studies, i.e., 8 , most of which were retrospective. However, validated systematic review methods were used and the data were reported using standard reporting guidelines, including the guidelines of the Handbook for Diagnostic Test Accuracy Reviews published by the Cochrane Collaboration (13). Second, as significant heterogeneity was also present in the detection rate of MCSG in these studies, any interpretations should be made cautiously. Third, the majority of the included studies focused on the entire cervical sympathetic chain, not only MCSG primarily. Therefore, there was a lack of concentrated information about the MCSG. Finally, because of the approximate $50 \%$ detection rate, improving complication rates might be limited.

In conclusion, understanding the characteristics and variations of the MCSG could minimize complications and maximize efficacy during surgery or USguided procedures. 


\section{References}

1. Civelek E, Karasu A, Cansever T, Hepgul K, Kiris T, Sabanci A, Canbolat A. Surgical anatomy of the cervical sympathetic trunk during anterolateral approach to cervical spine. Eur Spine J 2008; 17:991-995.

2. Ebraheim NA, Lu J, Yang H, Heck BE, Yeasting RA. Vulnerability of the sympathetic trunk during the anterior approach to the lower cervical spine. Spine 2000; 25:1603-1606.

3. Pishdad GR, Pishdad P, Pishdad R. Horner's syndrome as a complication of percutaneous ethanol treatment of thyroid nodule. Thyroid 2011; 21:327-328.

4. Messika O, Telman G. Horner syndrome after lymph node fine needle aspiration. Acta Cytol 2009; 53:487-488.

5. $\quad \mathrm{Na} D G$, Lee JH, Jung SL, Kim J-H, Sung JY, Shin JH, Kim E-K, Lee JH, Kim DW, Park JS, Kim KS, Baek SM, Lee Y, Chong S, Sim JS, Huh JY, Bae JI, Kim KT, Han SY, Bae MY, Kim YS, Baek JH. Radiofrequency ablation of benign thyroid nodules and recurrent thyroid cancers: Consensus statement and recommendations. Korean J Radiol 2012; 13:117-125.

6. Shin JE, Baek JH, Lee JH. Radiofrequency and ethanol ablation for the treatment of recurrent thyroid cancers: Current status and challenges. Curr Opin Oncol 2013; 25:14-19.

7. Katritsis ED, Lykaki-Anastopoulou G, Papadopoulos NJ. Anatomical observations on the intermediate ganglion of the cervical sympathetic trunk (based on 232 specimens). Anat Anz 1983; 154:33-38.

8. Kawashima T. The autonomic nervous system of the human heart with special reference to its origin, course, and peripheral distribution. Anat Embryol (Berl) 2005; 209:425-438.

9. Kiray A, Arman C, Naderi S, Güvencer M, Korman E. Surgical anatomy of the cervical sympathetic trunk. Clin Anat 2005; 18:179-185.

10. Saylam CY, Ozgiray E, Orhan M, Cagli S, Zileli M. Neuroanatomy of cervical sympathetic trunk: A cadaveric study. Clin Anat 2009; 22:324-330.

11. Shin JE, Baek JH, Ha EJ, Choi YJ, Choi WJ, Lee JH. Ultrasound features of middle cervical sympathetic ganglion. Clin J Pain 2015; 31:909-913.

12. Yin Z, Yin J, Cai J, Sui T, Cao X. Neuroanatomy and clinical analysis of the cervical sympathetic trunk and longus colli. J Biomed Res 2015; 29:501-507.
13. Whiting $P$, Rutjes AW, Reitsma JB, Bossuyt PM, Kleijnen J. The development of QUADAS: A tool for the quality assessment of studies of diagnostic accuracy included in systematic reviews. BMC Med Res Methodol 2003; 3:25.

14. Suh $\mathrm{CH}$, Park SH. Successful ublication of systematic review and meta-analysis of studies evaluating diagnostic test accuracy. Korean J Radiol 2016; 17:5-6.

15. Kim KW, Lee J, Choi SH, Huh J, Park SH. Systematic review and meta-analysis of studies evaluating diagnostic test accuracy: A practical review for clinical researchers-part I. General guidance and tips. Korean J Radiol 2015; 16:1175-1187.

16. Lee J, Kim KW, Choi SH, Huh J, Park $\mathrm{SH}$. Systematic review and meta-analysis of studies evaluating diagnostic test accuracy: A practical review for clinical researchers-part II. Statistical methods of meta-analysis. Korean J Radiol 2015; 16:1188-1196.

17. Higgins J, Green S; The Cochrane Collaboration. Cochrane Handbook for Systematic Reviews of Interventions. Version 5.1.0 [Updated March 2011]. http:// handbook-5-1.cochrane.org. Date Accessed o8/15/2015.

18. Higgins JP, Thompson SG, Deeks JJ, Altman DG. Measuring inconsistency in meta-analyses. BM] 2003; 327:557-560.

19. Egger M, Davey Smith G, Schneider M, Minder C. Bias in meta-analysis detected by a simple, graphical test. BMJ 1997; 315:629-634.

20. Duval S, Tweedie R. Trim and fill: A simple funnel-plot-based method of testing and adjusting for publication bias in meta-analysis. Biometrics 2000; 56:455-463.

21. Raffaelli M, lacobone M, Henry JF. The "false" nonrecurrent inferior laryngeal nerve. Surgery 2000; 128:1082-1087.

22. Furlan JC. Sympathetic fiber origin of the superior laryngeal nerve and its branches: an anatomic study. Clin Anat 2002; 15:271-275.

23. Maranillo E, Vazquez T, Quer M, Niedenführ MR, Leon X, Viejo F, Parkin I, Sanudo JR. Potential structures that could be confused with a nonrecurrent inferior laryngeal nerve: An anatomic study. Laryngoscope 2008; 118:56-6o.

24. Gofeld M, Bhatia A, Abbas S, Ganapathy $S$, Johnson M. Development and validation of a new technique for ultrasoundguided stellate ganglion block. Reg Anesth Pain Med 2009; 34:475-479.
25. Usui Y, Kobayashi T, Kakinuma H, Watanabe K, Kitajima T, Matsuno K. An anatomical basis for blocking of the deep cervical plexus and cervical sympathetic tract using an ultrasound-guided technique. Anesth Analg 2010; 110:964-968.

26. Stark ME, Safir I, Wisco JJ. Probabilistic mapping of the cervical sympathetic trunk ganglia. Auton Neurosci 2014; 181:79-84.

27. Hoffman $\mathrm{HH}$. An analysis of the sympathetic trunk and rami in the cervical and upper thoracic regions in man. Ann Surg 1957; 145:94-103.

28. Pick J. The Autonomic Nervous System: Morphological, Comparative, Clinical, and Surgical Aspects. Lippincott, Philadelphia, 1970.

29. Lee JY, Lee JH, Song JS, Song MJ, Hwang S-J, Yoon RG, Jang SW, Park JE, Heo YJ, Choi YJ, Baek JH. Superior cervical sympathetic ganglion: Normal im-

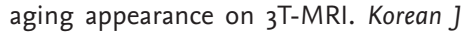
Radiol 2016; 17:657-663.

30. Lee JH, Cheng K-L, Choi YJ, Baek JH. High-resolution imaging of neural anatomy and pathology of the neck. Korean J Radiol 2017; 18:180-193.

31. Lyons AJ, Mills CC. Anatomical variants of the cervical sympathetic chain to be considered during neck dissection. $\mathrm{Br}$ J Oral Maxillofac Surg 1998; 36:180-182.

32. Shin JH, Baek JH, Ha EJ, Lee JH. Radiofrequency ablation of thyroid nodules: Basic principles and clinical application. Int J Endocrinol 2012; 2012:919650.

33. Ha EJ, Baek JH, Lee JH. Ultrasonography-based thyroidal and perithyroidal anatomy and its clinical significance. Korean J Radiol 2015; 16:749-766.

34. Monchik JM, Donatini G, lannuccilli J, Dupuy DE. Radiofrequency ablation and percutaneous ethanol injection treatment for recurrent local and distant well-differentiated thyroid carcinoma. Ann Surg 2006; 244:296-304.

35. An HS, Vaccaro A, Cotler JM, Lin S. Spinal disorders at the cervicothoracic junction. Spine (Phila Pa 1976) 1994; 19:2557-2564.

36. Giombini S, Solero CL. Considerations on 100 anterior cervical discectomies without fusion. In: Grote W, Kasner M, Clar HE, Klinger M, Nau HE (eds). Surgery of Cervical Myelopathy. Infantile Hydrocephalus: Long-Term Results. SpringerVerlag Berlin Heidelberg, Berlin 1980, pp 302-307. 
37. Hankinson HL, Wilson CB. Use of the operating microscope in anterior cervical discectomy without fusion. J Neurosurg 1975; 43:452-456.

38. Johnston FG, Crockard HA. One-stage internal fixation and anterior fusion in complex cervical spinal disorders. J Neurosurg 1995; 82:234-238.

39. Saunders RL, Bernini PM, Shirreffs TG Jr., Reeves AG. Central corpectomy for cervical spondylotic myelopathy: A consecutive series with long-term follow-up evaluation. J Neurosurg 1991; 74:163-170.
40. Smith GW, Robinson RA. The treatment of certain cervical-spine disorders by anterior removal of the intervertebral disc and interbody fusion. J Bone Joint Surg Am 1958; 40-A:607-624.

41. Tew JM Jr., Mayfield FH. Complications of surgery of the anterior cervical spine. Clin Neurosurg 1976; 23:424-434.

42. Narouze S. Beware of the "serpentine" inferior thyroid artery while performing stellate ganglion block. Anesth Analg 2009; 109:289-290.
43. Al-Abbadi MA, Youngberg G, Al-Lozi M. Horner syndrome after lymph node fine needle aspiration: Which is the culprit? Acta Cytol 2010; 54:1058-1059.

44. Loke SC, Karandikar A, Ravanelli M, Farina $\mathrm{D}$, Goh JP, Ling EA, Maroldi R, Tan TY. Superior cervical ganglion mimicking retropharyngeal adenopathy in head and neck cancer patients: MRI features with anatomic, histologic, and surgical correlation. Neuroradiology 2016; 58:45-50. 